\title{
Effect of Nitrogen Ion Implantation on the Surface Hardness, Corrosion Rate, and Crystal Structure of Pure Aluminium
}

\author{
Dwi Priyantoro $^{1}$, Emy Mulyani ${ }^{2, *}$, Tjipto Sujitno ${ }^{2}$ \\ ${ }^{1}$ Electro-mechanical Department, Polytechnic Institute of Nuclear Technology, Yogyakarta, Indonesia \\ ${ }^{2}$ Particle Physics Department, Center for Accelerator Science and Technology, Yogyakarta, Indonesia
}

\section{Email address:}

priyantorosttn@gmail.com (D. Priyantoro),emymulya@batan.go.id (E. Mulyani), tjiptosujitno@batan.go.id (T. Sujitno)

${ }^{*}$ Corresponding author

\section{To cite this article:}

Dwi Priyantoro, Emy Mulyani, Tjipto Sujitno. Effect of Nitrogen Ion Implantation on the Surface Hardness, Corrosion Rate, and Crystal Structure of Pure Aluminium. Advances in Materials. Vol. 8, No. 4, 2019, pp. 137-141. doi: 10.11648/j.am.20190804.12

Received: July 22, 2019; Accepted: September 16, 2019; Published: October 9, 2019

\begin{abstract}
The weakness of aluminium and its alloys are relative low hardness and wear resistance. To improve this weakness a nitrogen ion implantation technique has been carried out. For the purpose, an ion implantation process was carried out for various of dose such as $0.578 \times 10^{16}$ ion $/ \mathrm{cm}^{2}, 0.706 \times 10^{16}$ ion $/ \mathrm{cm}^{2}, 0.842 \times 10^{16}$ ion $/ \mathrm{cm}^{2}, 0.970 \times 10^{16}$ ion $/ \mathrm{cm}^{2}$, and $1.106 \times 10^{16}$ ion $/ \mathrm{cm}^{2}$ at a certain energy and beam current, $60 \mathrm{keV}$ and $75 \mu \mathrm{A}$, respectively. Hardness test was performed using microhardness tester, the corrosion resistance was tested using the electrochemical method, and the crystal structure was analyzed using X-ray diffraction. From the hardness test result, it can be concluded that the optimum hardness in order of $37.5 \mathrm{VHN}$ was achieved at an ion dose of $0.83 \times 10^{17} \mathrm{ion} / \mathrm{cm}^{2}$. While the hardness for the untreated sample was $18.70 \mathrm{VHN}$. It meant, there is an increasing hardness by a factor of 100,53\%. At these conditions, the corrosion rate reduces from $0.012 \mathrm{mmpy}$ to $0.011 \mathrm{mmpy}$ or reduce by a factor of $8.3 \%$. Based on the XRD analysis, it can be obtained the AlN phase is formed through the peaks at 2-theta was $39.37^{\circ}$ $(111), 45.76^{\circ}(200)$, and $66.88^{\circ}(202)$.
\end{abstract}

Keywords: Ion Implantation, Hardness Test, XRD, Corrosion Rate, Pure Aluminium

\section{Introduction}

Aluminium and its alloys have been widely used in the chemical, aerospace, food, automotive, electronics and marine industries due to their low price, high wear resistance, low density and great strength [1]. However, the application of Aluminium alloys is restricted by their high chemical activity and potentially poor corrosion resistance. Although the formation of an oxide layer increases the corrosion resistance of the alloy, this layer is easily eroded. This erosion can be attributed to defects in the oxide layers. Defects are more likely to be exposed to the atmosphere and suffer attacks from chloride ions, leading to more serious corrosion cracks $[1,2]$.

There is a growing interest in extending the use of aluminium alloys, especially in motor vehicles components, in order to achieve better energy efficiencies through weight reduction. But the relatively low hardness, and low wear resistance of Aluminium alloys make these alloys especially prone to wear in sliding and rolling contact situations, which is a major constraint for their use. Although requirements for these applications can be met through the use of Aluminium matrix composites, the cost of manufacturing these components makes the application of surface engineering methods a more cost-effective approach $[2,3]$.

To improve the quality of the Aluminium surface, there are various types of surface coatings available to engineers, some technique can be applied such as Physical Vapour Deposition (PVD), Chemical Vapour Depostion (CVD) or Ion Implantation (II). Several studies showed that nitrogen ion implantation could increase tribology properties such as hardness, wear resistance, fatigue life and corrosion resistance [4-7]. Some elements such as N, Ti, and Cr increase occurrence of new phase formation and microstructure alteration as well as the chemical and mechanical properties [8]. However, among those ions, the ion that is an interstitial solute which can contribute to the formation of Aluminium nitride phase on the surface [8]. The importance of Aluminium nitride (AlN) is due to its excellent strength-to weight ratio, reasonably good corrosion resistance [9], extreme hardness, its electrical 
insulating properties (a band gap approximately $6.3 \mathrm{eV}$ ) and its high melting point (about $2400^{\circ} \mathrm{C}$ [10]). Its light weight, high shearing strength, and its high corrosion resistance [11].

Ion implantation is a surface modification technique by which atoms or molecules are ionized, accelerated in an electrostatic field, and implanted into the surface of a substrate. This technique produces a modification in the structure of targets (metal) surface by formation of new crystalline phases, metastable or amorphous, and those to improve the surface properties [3]. A great advantage is the negligible effect of ion implantation on the dimensions of the treated element; hence, the process can be applied in the final stage of manufacturing of products that already have their final dimensions [12]. Besides improvement of tribological properties, ion implantation contributes to an increase in mechanical strength. This is associated with an increase in the microhardness of the implanted samples. The implantation process is accompanied with appearance of compressive stresses and inclusions of nitrides. The implantation-induced hardening process depends on the type and dose of implanted ions and the temperature of the implanted material. The introduction of new atoms in the crystal lattice is not the only effect of ion implantation but also, the damage originated in the crystal structure of the target by the energetic collision cascades must also be taken into account [13].

As each ion penetrates the target, it undergoes a series of collisions displacing host atoms along the way. Both the ion and dislodged target atoms can continue and cause further damage, and so the energy is spread over many moving particles. Therefore, after implantation of high doses of ions an initially crystalline target will be so perturbed that it will have changed to a highly disordered state [14]. The amount of crystallographic damage can be enough to cause the partial amorphization of the metal surface, depending on the dose, energy, temperature (governing self-annealing that can occur to repair some or all of the damage as it is generated) and ion species (heavy ions displace a greater volume of target atoms per ion [15]. Finally, the implantation of high dose of ions induces significant compressive stress that can contribute to the blocking of the fissures and close the channels of corrosion [2].

A great advantage of ion implantation technique compare to others method is the negligible effect of ion implantation on the dimensions of the treated element; hence, the process can be applied in the final stage of manufacturing of products that already have their final dimensions $[16,17]$.

\section{Methodology}

In this experiments rectangular AA 5086 Aluminium plate was cut into specimens $4 \mathrm{~mm} \times 14 \mathrm{~mm}$ in size in a disc shape using wather jet cutting. The specimens were grounded with $\mathrm{SiC}$ papers from \# 80 up to 5000 mesh and polished mechanically with $1 \mu \mathrm{m}$ diamond paste. The polished specimens were washed with acetone in an ultrasonic cleaner and dried at room temperature. The samples were implanted by using $150 \mathrm{keV} / 2 \mathrm{~mA}$ ion implanter that's performed at dose $3.107 \times 10^{16} \mathrm{ion} / \mathrm{cm}^{2}, 3.148 \times 10^{16} \mathrm{ion} / \mathrm{cm}^{2}, 3.728 \times 10^{16} \mathrm{ion} / \mathrm{cm}^{2}$, $4.039 \times 10^{16} \mathrm{ion} / \mathrm{cm}^{2}$ and $4.35 \times 10^{16} \mathrm{ion} / \mathrm{cm}^{2}$ and at $60 \mathrm{keV}$ of ions energy. The increase of the sample temperature was ensured solely by incoming ion beam without any additional heating. The chemical compositions of AA5086-is $0.4 \% \mathrm{Si}$, $0.5 \% \mathrm{Fe}, 0.1 \% \mathrm{Cu}, 0.35 \% \mathrm{Mn}, 4.0 \% \mathrm{Mg}, 0.15 \% \mathrm{Cr}, 0.25 \% \mathrm{Zn}$, $0.15 \% \mathrm{Ti}$, balance Al.

\section{Result and Discussion}

\subsection{Analysis of the Hardness}

The effect of nitrogen ion implantation in micro hardness properties of samples was tested by using Vickerss Tester Microhardness Tester type MTX7 type (see Figure 1). It can be concluded that the hardness of samples improves after nitrogen ion implantation and extend of improvement increases with dose. The maximum hardness appears at a nitrogen ion dose of $0.706 \times 10^{16} \mathrm{ion} / \mathrm{cm}^{2}$. In this condition, the hardness increases from 18.7 VHN (raw material) to optimum $37.50 \mathrm{VHN}$ or increase by factor $100.53 \%$, while the corrosion rate reduces from dose 0,012 mmpy to 0,011 mmpy or reduces by factor $8.3 \%$. Over this dose the hardness decreases, this decrease is may be caused by defect due to the excess ion irradiation. Effect of nitrogen ions doses on the surface hardness of implanted samples is presented in Figure 1.

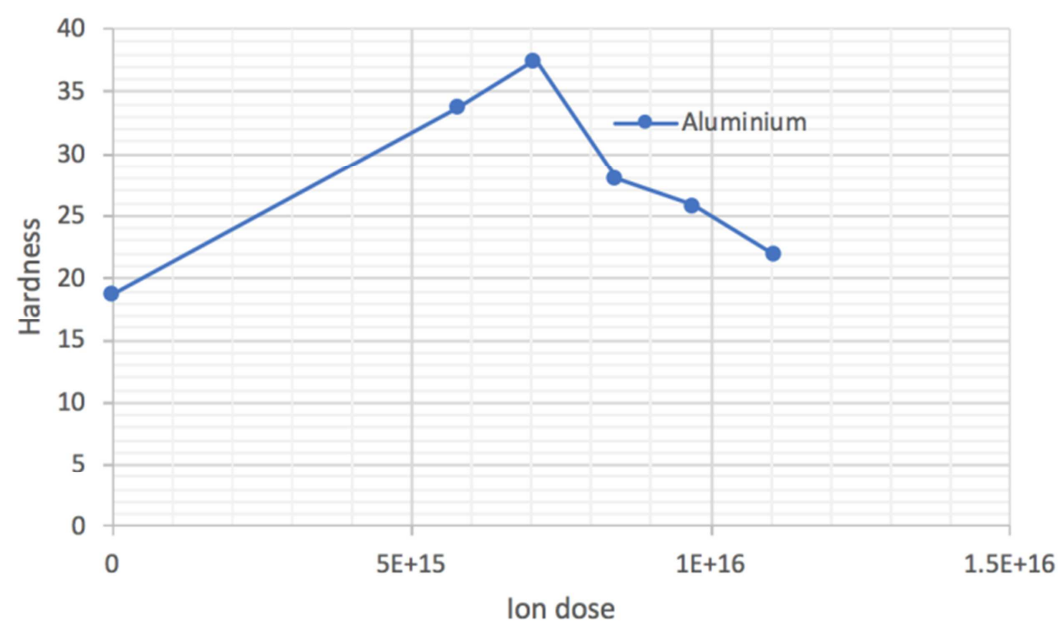

Figure 1. Effect nitrogen ions doses on the surface hardness of pure aluminium. 


\subsection{Corrosion Measurement}

Electrochemical measurement were carried by using three electrode Potensio Galvanostat VersStat 4 type in $3.5 \% \mathrm{NaCl}$ solution. Tafel plot measurement were carried out using conventional three electrode Pyrex glass cell with platinum counter electrode and $\mathrm{Ag} / \mathrm{AgCl}$ electode as reference electrode. Finaly, un-impalanted and implanted specimens (at optimum conditions) of $1 \mathrm{~cm}^{2}$, surface area were exposed to corrosion medium of $3.5 \% \mathrm{NaCl}$ solution. The potensidynamic current potential curves were recorded by polarizing the specimen to $-250 \mathrm{mV}$ cathodically and $250 \mathrm{mV}$ anodically with respect to open circuit potential at scan rate of $5 \mathrm{mVs}^{-1}$. The

\subsection{E-01}

1.00E-02

\section{$1.00 \mathrm{E}-03$}
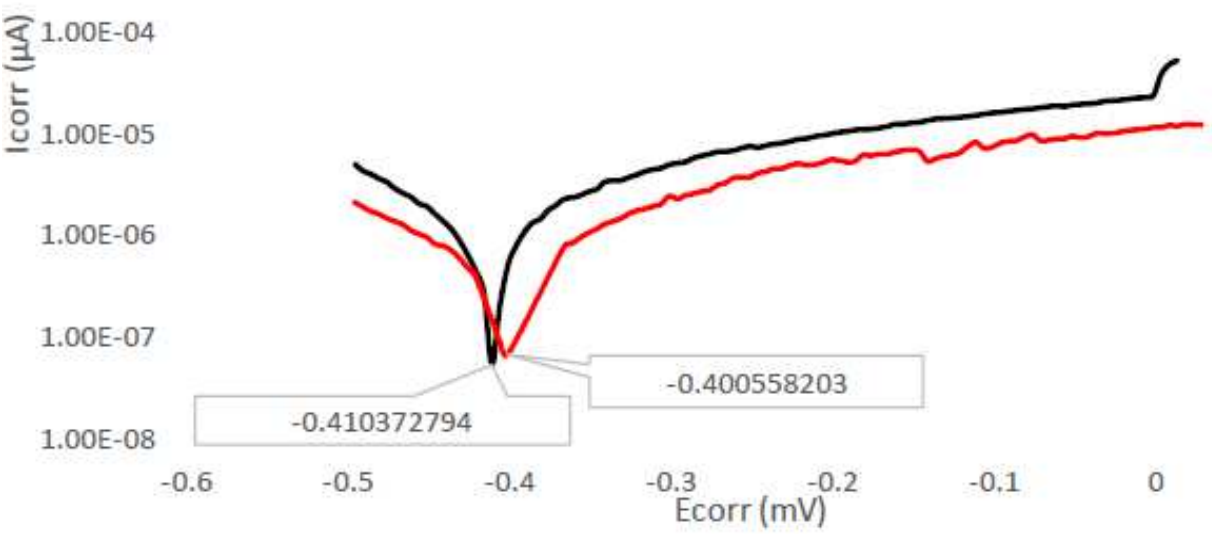

potensiodynamic polarization parameters like corrosion potential $\left(\mathrm{E}_{\text {corr }}\right)$, corrosion current $\left(\mathrm{i}_{\text {corr }}\right)$, polarization resistance $\left(R_{p}\right)$, anodic and cathodic slopes (ba and bc), and corrosion rate are calculated from Tafel plots. Potentio dynamic polarization curves for un-implanted and implanted specimens at optimum conditions is presented in Figure 2. It's observed that there is shifting in the corrosion potential $\mathrm{E}_{\text {corr }}$ from $-0,410,378 \mathrm{mV}$ to $-399,951 \mathrm{mV}$, and there is a reducing in corrosion rate from $0.012 \mathrm{mmpy}$ to $0,011 \mathrm{mmpy}$, or there is an increasing corrosion rate by factor $8.3 \%$. The positive shift in the corrosion potential Ecorr, indicates that anodic process is much more affected than the cathodic.

Figure 2. Potentio dynamic polarization curves for un implanted and implanted samples of pure aluminium in $3.5 \% \mathrm{NaCl}$ solution.

\subsection{XRD Analysis of Implanted and Un-implanted Samples}

The phase composition of un-implanted and implanted samples was analyzed using X-rays in the $\theta-2 \theta$ mode and $\lambda=$ $1.548 \AA$ of $\mathrm{Cu} \mathrm{K} \mathrm{K}_{\alpha}$ radiation. Figure 3 or Table 1 shows the XRD patterns of un-implanted samples materials. From the patterns shown that four peaks (111), (200), (202) and (301) with cubic structures at $2 \theta=38.71^{\circ}, 45.07^{\circ}, 65.14^{\circ}$, and $78.48^{\circ}$ respectively which were related to the aluminium alloys substrate with the main elements is Aluminium (Al) and after being analyzed using Crystallography Open Database (COD), entry number 96-901-2003 code, it's observed that the phase is $100 \%$ of Al. For implanted samples at optimum conditions which is presented in Table 2 or Figure 4 and after being analyzed using Crystallography Open Database (COD), entry number 96-152-096 code, it's observed that the phase is $100 \%$ of AIN.

Table 1. Peaks positions of un-implanted materials of AA 5086.

\begin{tabular}{llll}
\hline $\mathbf{2 \theta}_{\text {meas. }}$ & $\mathbf{2 \theta}_{\text {cal. }}$ & Intensity & hkl \\
\hline 38.71 & 38.538 & 100 & 111 \\
45.07 & 44.798 & 469 & 200 \\
65.14 & 65.215 & 263 & 202 \\
78.48 & 78.3866 & 278 & 301 \\
\hline
\end{tabular}

Table 2. Peaks positions of implanted materials of AA 5086.

\begin{tabular}{llll}
\hline $\mathbf{2 \theta}_{\text {meas. }}$ & $\mathbf{2 \theta}_{\text {cal. }}$ & Intensity & hkl \\
\hline 39.7 & 39.4 & 275 & 111 \\
45.76 & 45.81 & 1000 & 200 \\
66.88 & 66.80 & 497 & 202 \\
\hline
\end{tabular}




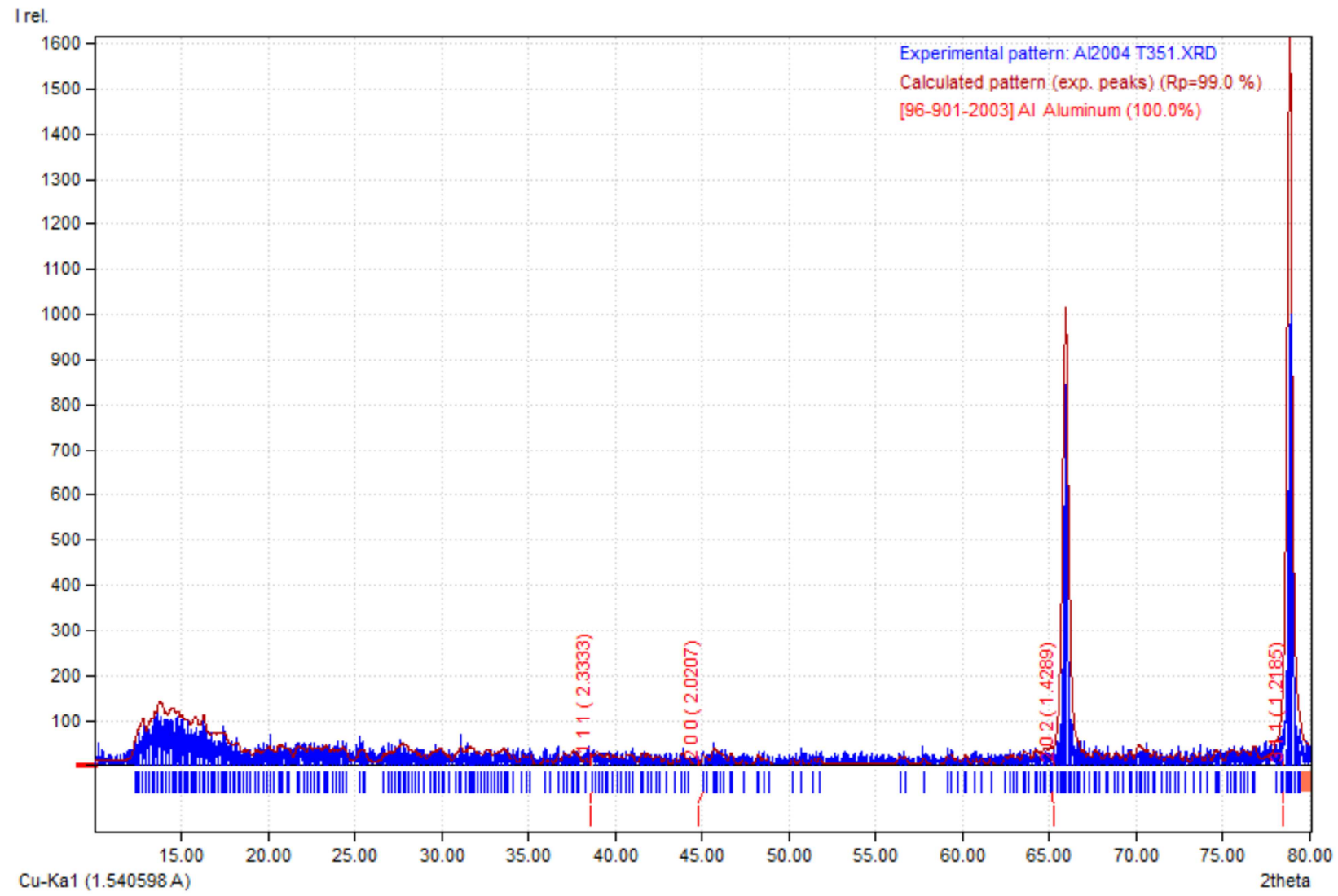

Figure 3. Diffractogram of the un-implanted samples materials of Aluminium.

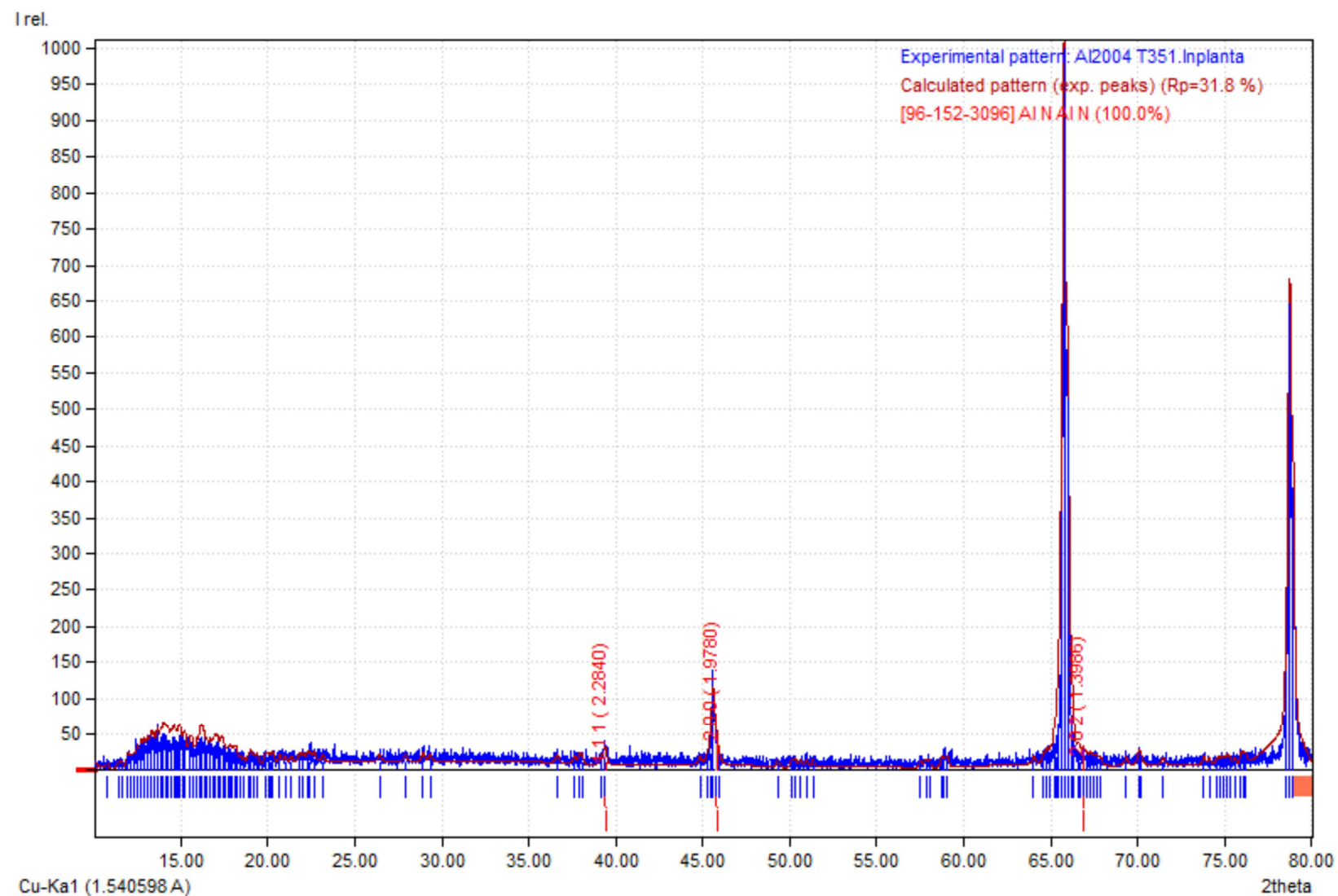

Figure 4. Diffractogram of implanted samples with nitrogen ions at energy of $60 \mathrm{keV}$ for 54 minutes of implantation time or $0.706 \times 10^{-16}$ ion $/ \mathrm{cm}^{2}$ of ions dose $(100 \%$ of AlN phase). 


\section{Conclusion}

Based on the experiments carried out, it can be concluded as follow:

The hardness of un-implanted materials is $18.70 \mathrm{VHN}$. The optimum hardness order of $37.50 \mathrm{VHN}$ or increases by factor $100.53 \%$, appears at a nitrogen ion dose of $0.706 \times 10^{16} \mathrm{ion} / \mathrm{cm}^{2}$. Over this dose, the hardness decreases, this may be caused by defects due to the excess ion irradiation. Increasing in hardness is mainly caused by the formation of Aluminium Nitride (AIN) new phase, this phase is indicated by XRD analysis shown by Figure 2 and Figure 3.

In the corrosion test, it's observed that there is shifting in the corrosion potential $\mathrm{E}_{\text {corr }}$ from $-0,410,378 \mathrm{mV}$ to $399,951 \mathrm{mV}$, and there is a reducing in corrosion rate from $0.012 \mathrm{mmpy}$ to $0,011 \mathrm{mmpy}$, or there an incrasing in corrosion rate by factor $8.3 \%$. The positive shift in the corrosion potential Ecorr, indicates that anodic process is much more affected than the cathodic.

\section{Acknowledgements}

The authors gratefully thank the Centre Accelerator Science and Technology, National Nuclear Energy Agency (CAST-NNEA) for the funding and facilities during this research. The authors also thank to Mr. Suprapto and Mrs. Wiwien Andriyanti for their discussion and also to $\mathrm{Mr}$. Muhamad Aziz Aljabar, Agus Wijayanto and Mrs Vika Arwida for their assistance during this research.

\section{References}

[1] Jingyi Yue, Yan Cao, Corrosion Prevention by Applied Coatings on Aluminium Alloys in Corrosive Environments, International journal of electrochemical science 10 (7): 5222-5237, June 2015).

[2] J. Wood, Gautam Majumdar, Ion Implantation, in Reference Module in Materials Science and Materials Engineering, 2016.

[3] R. Figueroa, C. M. Abreu, M. J. Cristóbal, G. Pena, Effect of nitrogen and molybdenum ion implantation in the tribological behavior of AA7075 Aluminium alloy, Wear 276-277, 53-60, 2012.

[4] Bandriyana, Agus Hadi Ismoyo, Tjipto Sujitno, A. Dimyati, Microstructure and, oxidation behavior of high strength steel AISI 410 implanted with nitrogen ion, AIP Conference Proceedings 1725, 020010 (2016).

[5] Nurdin Ali, Mohamad Ali Fulazzaky, Muhammad Sukri Mustapa, Mohd Imran Ghazali, Muhammad Ridhaa, Tjipto Sujitno, Assessment of fatigue and corrosion fatigue behaviours of the nitrogen ion implanted CpTi, International Journal of Fatigue 61, 184-190, 2014.
[6] Agung Setyo Darmawan, Waluyo Adi Siswanto, Tjipto Sujitno, Comparison of Commercially Pure Titanium Surface Hardness Improvement by Plasma Nitrocarburizing and Ion Implantation, Advanced Materials Research 789: 347-351, August 2013.

[7] Nurdin Ali, Mohammad Sukri Mustapa, Mohd Imran Ghazali, Tjipto Sujitno, Muhammad Ridha, Fatique Life Prediction of Commercially Pure Titanium After Nitrogent Ions Implantation, International Journal of Automotive and Mechanical Engineering 7 (1): 1007-1014, $\quad$ DOI: 10.15282/ijame.7.2012.16.0081, May 2013.

[8] Ainun Nikmah, Djoni Izak Rudyardjo, Jan Ady, Ahmad Taufiq, Studies on Density, Corrosion Rate and Hardness Characteristics of Stainless Steel Implanted by Nitrogen Ion, IOP Conference Series Materials Science and Engineering 515: 012018, April 2019.

[9] P. Vijaya Kumar, et al. Microstructure mechanical and corrosion behavior of high strength AA 7075, aluminium alloy friction ststir of post weld treatment, Defence Technology 11, 362-369, 2015.

[10] GHORANNEVISS Mahmood, SARI Amir H., DORRANIAN Davoud, KHORSHID Pejman, S. HAJIHOSSEINI G. Hassan, SHOKOUHY Ali and HESABI Maryam, Nitrogen Ion Implantation in Pure Aluminium, J. Plasma Fusion Res. SERIES, Vol. 7 (2006) 303-306).

[11] Youming Liu Liu he Li, Ming Xu Xun Ca Qiulong Chen Yawei $\mathrm{Hu}$ Paul K. Chu, Effects of nitrogen ion implantation and implantation energy on surface properties and adhesion strength of TiN films deposited on Aluminium by magnetron sputtering, Materials Science and Engineering: A, Volume 415, Issues 1-2, 15 January 2006, Pages 140-144.

[12] P Budzyski et al 2016, The influence of nitrogen ion implantation on microhardness of the Stellite 6 alloy IOP Conf. Ser.: Mater. Sci. Eng. 148012046.

[13] Muhammad Shahnawaz, S Bashir, Muhammad Ahsan Shafique and Hussain, 2018, Study the effects of nitrogen ion implantation on structural and mechanical properties of AA7075, Materials Research Express, Volume 5 Number 7, Published 4 July 2018 (C) 2018 IOP Publishing Ltd.

[14] Manouchehrian, M. M. Larijani and B. Banagar 2014, Influence of Energy Nitrogen Ion Implantation on Structural and Mechanical Properties of Chromium Thin Film, Int. J. Thin Fil. Sci. Tec. 3, No. 2, 67-70.

[15] K. Takeda, K. Mitsui, H. Tobushi, N. Levintant-Zayonts, S. Kucharski, 2013, Influence of nitrogen ion implantation on deformation and fatigue properties of TiNi shape memory alloy wire, Arch. Mech., 65, 5, pp. 391-405, Warszawa.

[16] Jingyi Yue, Yan Cao, Corrosion Prevention by Applied Coatings on Aluminium Alloys in Corrosive Environments, Int. J. Electrochem. Sci., 10 (2015) 5222-5237.

[17] Raid, S. Pavan, V. Fridrici, C. Poilâne, Ph. Kapsa,. Temperature Effect on the Kinetic Alumina Layer Growth on 5086 Aluminium Substrate, MECHANIKA. 2017 Volume 23 (6): 923-930. 